\title{
Associations Between Transgender Identity, Sleep, Mental Health and Suicidality Among a North American Cohort of College Students
}

This article was published in the following Dove Press journal: Nature and Science of Sleep

\author{
Shelley Hershner (D) \\ Erica C Jansen ${ }^{2}$ \\ Ronald Gavidia I \\ Lisa Matlen ${ }^{3}$ \\ Mary Hoban ${ }^{4}$ \\ Galit Levi Dunietz' \\ 'Sleep Disorders Center, Department of \\ Neurology, University of Michigan, Ann \\ Arbor, MI, USA; ${ }^{2}$ Department of \\ Nutritional Sciences, University of \\ Michigan School of Public Health, Ann \\ Arbor, MI, USA; ${ }^{3}$ Department of \\ Pediatrics; Sleep Disorder Center, \\ University of Michigan, Ann Arbor, MI, \\ USA; ${ }^{4}$ American College Health \\ Association, Research Office, Silver \\ Spring, MD, USA
}

Purpose: The purpose of this study is to examine the associations between transgender identity, sleep, and mental health among a North American cohort of cisgender and transgender college students.

Participants and Methods: This cross-sectional study surveyed 221,549 North American college students from the 2016-2017 American College Health Association-National College Health Assessment II. Bivariate and multivariable analysis examined associations among transgender identity and outcomes of insomnia symptoms, daytime sleepiness, sleep disorder diagnoses and treatments. Mental health outcomes included mood symptoms, suicidal behaviors, anxiety and depression diagnoses and treatments.

Results: Transgender identity was reported by $1.6 \%(\mathrm{n}=3471)$ of United States (US) and $1.7 \%(n=717)$ Canadian students, respectively. Mean age was $22.5 \pm 6$. Transgender college students have an increased prevalence of daytime sleepiness, insomnia symptoms, diagnoses and/or treatment of insomnia and other sleep disorders as compared to cisgender college students. Mental Health symptoms are more prevalent with a 2-fold increase in depression and anxiety and nearly a 4-fold increase in suicide attempts among transgender students. A higher burden of mood symptoms exists among transgender college students in the US in comparison to Canadian students.

Conclusion: Transgender college students have an alarmingly high rate of mood, sleep disturbances and sleep diagnoses, and suicidality. Colleges and universities must provide sufficient resources to address the sleep and mental health needs of transgender students. Institutions must adopt gender affirming policies that promote an inclusive environment. Increased allocation of resources and adoption of policies that enhance the physical and mental health of transgender students could improve sleep, mood, and potentially lower the suicide risk among a population that often experiences health inequities.

Keywords: transgender, college student, sleep, insomnia, mood, suicide
Correspondence: Shelley Hershner Sleep Disorders Center, Department of Neurology, University of Michigan, 728 Med Inn 1500 East Medical Center Drive, Ann Arbor, MI, USA

Tel +l 734-936-6295

Fax + I 734-936-5377

Email shershnr@umich.edu

\section{Plain Language Summary}

The college years can be a time of growth and opportunity for students, but despite these positive aspects, many college students struggle with mental health and sleep behaviors and daytime symptoms of tiredness and sleepiness. Transgender individuals are a population that face numerous challenges as many struggle with discrimination, isolation, and poor social support. Little research is available on the mental health and sleep of transgender college students. This study evaluated data from the American College Health Association-National College Health Assessment II (ACHA-NCHA II) survey from the United States of America (2016 and 2017) and Canada (2016). The ACHA-NCHA II is a voluntary, confidential survey 
that collects information on college students' self-reported health, health behaviors and perceptions. Our study reviewed students' gender identity, sleep, mood, and suicidality. Our results showed: Transgender college students were more likely to have 1) excessive daytime sleepiness, 2) symptoms of insomnia, and 3) a diagnosis of insomnia or other underlying sleep disorder. Mood disturbances are a significant issue as transgender college students were twice as likely to have depression and anxiety and 4 times as likely to have ever attempted suicide. These results suggest that colleges and universities must increase resources to address the mental health and sleep needs of transgender college students. It is vital that this population, which often faces numerous health disparities, experience a gender affirming and supportive college environment.

\section{Introduction}

The college years are a time of increased risk for sleep problems, mental health issues, and suicidality. ${ }^{1-4}$ Poor sleep among college students can negatively influence academic performance, immunity, risk-taking behaviors, obesity, and cardiometabolic health. ${ }^{5}$ Transgender individuals, and likely transgender college students, experience significant mental, physical, and psychologic health disparities for a multitude of reasons which at a minimum include discomfort with one's appearance and identity, limited availability of mental health services, discrimination, and social rejection. ${ }^{6-8}$ Due to these risk factors transgender college students could be at a higher risk than cisgender students for sleep disturbances and poor mental health. ${ }^{9-11}$

Transgender and gender diverse identity is used to describe individuals with gender behaviors, appearances, or identities that are incongruent with those culturally assigned to their birth sex. ${ }^{7,8,12}$ Gender diverse identities may be referred by many different terms, which include: transgender, non-binary, gender queer, gender fluid, gender creative, gender independent, or non-cisgender. ${ }^{7}$ Transgender men were assigned female sex at birth and identify as men, or as female-to-male (FTM). Transgender women were assigned male sex at birth and identify as women, or as male-to-female (MTF). Finally, cisgender refers to a gender identity congruent with the birth sex. As highlighted by the American Academy of Pediatrics policy statement: "These terms are not diagnoses; rather, they are personal and often dynamic ways of describing one's own gender experience." Currently, there is a multitude of terms used in the literature.
Transgender individuals are at risk for sleep disturbances due to a high prevalence of psychosocial stressors, discrimination, poor mood, and hormonal influences. ${ }^{9,13-15}$ The college campus does not necessarily provide psychosocial protection as transgender college students experience lower rates of acceptance, belonging, sense of safety, higher rates of discrimination, and exclusion on campus. ${ }^{9}$ In a systematic review, interpersonal discrimination is associated with poorer sleep; the underlying mechanisms require further research, but a study among Latino and Asian adolescents found an association with discrimination, perceived stress, and poor sleep. ${ }^{16,17}$ Transgender individuals report that hormonal treatment, gender dysphoria, and poor mood adversely impact their sleep. ${ }^{15}$ Difficulty with sleep impacts important life domains. Among transgender adults, poor sleep quality negatively affects quality of life. ${ }^{13}$ Short sleep in adult transgender individuals is associated with COPD and arthritis for FTM individuals while obesity and stroke risk is increased in multiple categories of transgender individuals. ${ }^{18}$ However, few studies have examined sleep among transgender college students.

Sex hormone therapy (SHT) is another risk for poor sleep. Many transgender individuals receive sex hormone therapy (SHT) as a gender affirming treatment for gender dysphoria, a clinical disorder when a transgender individual feels distress and/or incongruence with their assigned gender which interferes with social, school, or other areas of function. ${ }^{12}$ Although under-researched in the transgender population, mechanistically, sex hormone therapy can induce sleep disturbances, obstructive sleep apnea, and insomnia in transgender men and women. ${ }^{13,19,20}$ Despite some negative effects, sex hormone therapy can benefit mood and quality of life in transgender individuals. ${ }^{21}$

Transgender college students have a 4-fold increase in mental health problems. ${ }^{22}$ Mental health disorders which including anxiety, depression, suicidal ideation and attempts are more prevalent among the transgender population than their cisgender peers. ${ }^{11,22,23}$ Risk factors for mood issues among transgender college students are a negative cultural environment on campus, poor institutional support, and negative family and community experiences. ${ }^{24}$ Consequently, transgender students may feel marginalized even among the lesbian, gay, bisexual and queer (LGBQ) community. ${ }^{25}$ In the university health care environment, many transgender students report misgendering by therapists and health providers. ${ }^{26}$ In the Transgender Survey, one-third of adults (non-college) participants reported at least one 
negative experience related to being transgender within the health care environment. ${ }^{27}$ A quarter of participants did not see a doctor due to fear of misgendering or due to transgender-related insurance issues. ${ }^{27}$ Despite an increased need for physical and mental health support, transgender students have limited access to transgender competent medical, psychological services. ${ }^{8,9}$

At this time there is minimal research on the comparative experience of transgender college students in Canada and the United States. In 2018, Tyler Clementi Center analyzed 4 national surveys to better understand the experiences of queer-spectrum and trans-spectrum students attending US institutions. ${ }^{9}$ Transgender students' experienced poor mental health, discrimination, and often a negative campus environment. It also documented a significant lack of transgender-related resources as less than $15 \%$ of American colleges and universities had an employee with at least 20 hours a week dedicated to transgender students. Transgender and gender diverse identity students in Canadian post-secondary institutions also face discrimination and often a negative campus climate. ${ }^{28}$ In this sample, $22 \%$ of transgender students stated that they had been insulted, mistreated, ignored, or excluded because of their gender as compared to $6 \%$ of their peers. However, this study did not separate gender identity but rather investigated perceived gender, gender identity, and sexual orientation. These reports suggest that campus climate is sub-optimal in both countries however, there is no current comparison available.

Overall this data indicates that there is a paucity of research on the sleep, mental health, and suicidality of transgender college students. To fill this gap, the aim of this study was three-fold:

1. Estimate the proportion of transgender students that experience sleep and mental health disturbances, and daytime sleepiness as compared to cisgender college students.

2. Explore the proportion of transgender as compared to cisgender college students who experience mental health and sleep disturbances and daytime sleepiness in the United States as compared to Canada.

3. Establish the prevalence of self-reported suicidal behaviors in a college student transgender population.

We hypothesize that transgender college students would have worse sleep and mental health than cisgender college students. Additionally, we believe that sleep disturbances, poor mental health and suicidal behavior will be more prevalent among US students in comparison to their Canadian peers.

\section{Participants and Methods Study Design}

This was a cross-sectional study of the American College Health Association-National College Health Assessment II (ACHA-NCHA II) survey. Since the data were deidentified at both the institution and student level, approval was granted from the Institutional Review Board from the University of Michigan.

\section{Study Participants}

The study population included students from the United States (US) and Canada who attend institutions that enrolled in ACHA-NCHA-II survey. US schools participated during the 2016 and 2017 spring and fall semesters while Canadian schools participated during spring 2016 (Table 1).

\section{Survey}

The ACHA-NCHA II is a voluntary, confidential survey that collects information on college students' self-reported health, health behaviors and perceptions. Content includes 66 questions covering the domains of substance use, sexual, mental, and physical health, weight, nutrition, exercise, personal safety, violence, and impediments to academic performance. Individual institutions determine the number of students surveyed and if the survey will be web-based (the majority) or paper-based. Institutions pay to participate in the ACHANCHA II with ACHA member institutions receiving a discount. Students are invited to participate in the ACHANCHA survey via an e-mail sent by the ACHA or their school with a unique survey link. ${ }^{29}$ Non-responders were contacted with up 3 reminder messages. Complete details of survey

Table I American College Health Association-National College Health Assessment II Participating Schools and Number of Students

\begin{tabular}{|l|l|l|}
\hline & Schools & Students \\
\hline Fall 2016 & 51 & 33,512 \\
Spring 2016 (US Sample) & 137 & 95,761 \\
Spring 2016 (Canadian Sample) & 41 & 43,780 \\
Fall 2017 & 52 & 31,463 \\
Spring 2017 & 92 & 63,497 \\
\hline
\end{tabular}


administration are located: https://www.acha.org/NCHA/To

Participate/FAQs/NCHA/To Participate/FAQ.aspx?hkey= 7d4e7ad7-4103-44e2-8980-da5e30c70860.

\section{Survey Validity}

The NCHA-ACHA I and II have been repeatedly and systematically evaluated for its validity and reliability. ${ }^{30}$ These evaluations have demonstrated strong reliability and validity across survey items.

\section{Survey Questions}

Data on sleep and daytime function were collected through 7 questions on sleep, daytime function, and sleep diagnoses (Table 2). Daytime sleepiness was rated on a 5-point scale. The question, "Have you been diagnosed or treated by a professional for a sleep disorder or insomnia?" had dichotomous responses (yes/no). Five items queried about current sleep disturbances while responses to these questions corresponded to the number of symptomatic days in

Table 2 American College Health Association-National College Health Assessment II. Sleep and Mental Health Questions

\begin{tabular}{|c|c|c|c|}
\hline Measure & Questionnaire Items & $\begin{array}{l}\text { Possible } \\
\text { Responses }\end{array}$ & Categorized \\
\hline \multirow[t]{3}{*}{$\begin{array}{l}\text { Sleep } \\
\text { symptoms }\end{array}$} & $\begin{array}{l}\text { In the past } 7 \text { days: } \\
\text { I. Awakened too early and could not get back to sleep? } \\
\text { 2. Felt tired, dragged out, or sleepy during the day? } \\
\text { 3. Gone to bed because you just could not stay awake any longer? } \\
\text { 4. Had an extremely hard time falling asleep? } \\
\text { 5. Did you get enough sleep so that you felt } \\
\text { rested when you woke up in the morning? }\end{array}$ & $\begin{array}{l}\text { Days of the week } \\
(0-7 \text { days })\end{array}$ & $\begin{array}{l}\geq 3 \text { days in a week } \\
0-2 \text { days in a week }\end{array}$ \\
\hline & In the past 7 days, how much of a problem have you had with sleepiness? & $\begin{array}{l}\text { No problem at all } \\
\text { A little problem } \\
\text { More than a little } \\
\text { problem } \\
\text { A big problem } \\
\text { A very big problem }\end{array}$ & $\begin{array}{l}\text { Infrequent } \\
\text { - No problem at all } \\
\text { Sometimes } \\
\text { - A little problem } \\
\text { - More than a little problem } \\
\text { Frequent } \\
\text { - Big problem } \\
\text { - Very big problem }\end{array}$ \\
\hline & $\begin{array}{l}\text { Within the last } 12 \text { months, have you been diagnosed or treated by a professional } \\
\text { for either? }\end{array}$ & $\begin{array}{l}\text { Insomnia } \\
\text { Other sleep } \\
\text { disorder }\end{array}$ & Yes/No \\
\hline \multirow[t]{4}{*}{$\begin{array}{l}\text { Mental health } \\
\text { symptoms }\end{array}$} & $\begin{array}{l}\text { Have you ever? } \\
\text { I. Felt things were hopeless } \\
\text { 2. Felt overwhelmed by all you had to do } \\
\text { 3. Felt exhausted (not from physical activity) } \\
\text { 4. Felt very lonely } \\
\text { 5. Felt very sad } \\
\text { 6. Felt so depressed that it was difficult to function } \\
\text { 7. Felt overwhelming anxiety } \\
\text { 8. Felt overwhelming anger } \\
\text { 9. Intentionally cut, burned, or otherwise injured yourself } \\
\text { 10. Considered suicide } \\
\text { II. Attempted suicide }\end{array}$ & $\begin{array}{l}\text { No, never } \\
\text { No, not in } \\
12 \text { months } \\
\text { Yes, in the last } \\
2 \text { weeks } \\
\text { Yes, in the last } \\
30 \text { days } \\
\text { Yes, in the last } \\
12 \text { weeks }\end{array}$ & $\begin{array}{l}\text { Yes for any positive response (e.g not } \\
\text { never) }\end{array}$ \\
\hline & Have you ever been diagnosed with depression? & Yes/No & Yes/No \\
\hline & $\begin{array}{l}\text { Within the last } 12 \text { months, have you been diagnosed or treated by a professional } \\
\text { for either? } \\
\text { - Anxiety } \\
\text { - Depression }\end{array}$ & & \\
\hline & $\begin{array}{l}\text { Have you received psychological or mental health services from your current } \\
\text { college/university's Counseling or Health Service? }\end{array}$ & Yes/No & Yes/No \\
\hline
\end{tabular}


a week. This was categorized into $0-2$ days versus $\geq 3$ days for analysis as the diagnostic criteria for insomnia requires insomnia symptoms at least 3 days a week. Excessive daytime sleepiness has been defined as significant when experienced often (5-15/month) or almost always (16-30/ month) consistent with a weekly frequency of 3 or more days a week. ${ }^{31,32}$ Fourteen self-reported mental healthrelated questions included: "Have you had or felt hopeless, overwhelmed, sad, lonely, depressed, anxious, angry, selfharm, suicidal thoughts, or attempted suicide?" These were classified by frequency. A dichotomous response was used for the question if subjects had been diagnosed or treated by a professional for anxiety, depression, or had received counseling.

\section{Gender Identity}

Students identified their gender assigned at birth as well as their current gender. ${ }^{33}$ Information on gender identity was collected with three questions: 1. "What sex were you assigned at birth, such as on an original birth certificate," with a response of male or female 2. "Do you identify as transgender?" with a response of yes or no and 3. "Which term do you use to describe your gender identity?" The responses were woman, man, trans man, trans woman, genderqueer and another identity (please specify). Respondents were classified as cisgender male or female if their gender identity was consistent with their gender assigned at birth and responded "no" for transgender identity. Students who reported transgender identity were classified as transgender. If a student did not identify as transgender but had a difference between their assigned sex and gender identity were considered as nonbinary.

In the primary analyses only students who selfidentified as transgender were included in the initial analysis. In a sensitivity analysis, we included non-binary students or those students who did not identify as transgender, but reported a mismatch between their birth and assigned gender. ${ }^{33}$ In the US 328 subjects met that classification and 95 subjects in Canada.

\section{Covariates}

Potential confounders were selected a priori using directed acyclic graphs and previous literature. Demographic and college-related variables with an impact on mental health and health behaviors were included in adjusted analysis. ${ }^{30}$ Covariates included race/ethnicity, semester, and year in school, college size, Carnegie Classification which groups institutions of higher institutions into comparable degreegranting categories, campus setting (eg-very large city $>500,000)$ and region of the US. Region was not available for Canadian schools.

\section{Statistical Analysis}

Descriptive procedures (chi-square tests) were used to examine the distributions of students within sociodemographic categories according to transgender identity (cisgender versus transgender) and separately for the US and Canada.

In bivariate analysis, stratified by country, the proportion of students per each sleep disturbance were calculated for cisgender versus transgender participants. Logistic regression models were used to identify covariates that may confound the associations between transgender identity, sleep, and mood disturbances.

The associations between transgender identity, as the exposure, and sleep mental health as separate outcomes, was estimated with logistic regression models, adjusted for race/ethnicity, semester (the US only), college size, campus setting, Carnegie classification (the US only), region (the US only), and year in school. Formal interaction analysis was performed to examine if the country of origin moderates the association of sleep and mental health parameters among transgender individuals. We added to the regression models transgender identity and country as main effects, an interaction term for country*transgender identity, adjusting for potential confounders.

Finally, in sensitivity analyses, we added to the transgender group students who did not self-identify as transgender, but reported discordance between their assigned birth sex and gender identity. All analyses were performed in SAS v 9.4.

\section{Results}

In a cohort of 221,549 college students, 3471 and 717 $(1.6 \%$ and $1.7 \%)$ reported transgender identity in the US and Canada, respectively (Tables 3-5). Non-binary students or those students who did not identify as transgender, but reported a mismatch between their birth and assigned gender consisted of 423 participants (US 328 and Canada 95).

Cisgender students had similar mean age, regional distribution, and college type attendance. Different racial distribution, patterns of campus setting, Carnegie classification, and college size were observed between cisgender and transgender students. The majority of subjects were 
Table 3 US Sample: Bivariate Associations Between Transgender Identity, Demographic and College Characteristics in a Sample of 221, 549 College/University Students from the United States

\begin{tabular}{|c|c|c|c|c|}
\hline Student Characteristics & $\mathbf{N}$ & Cisgender (\%) $N=218,078$ & Transgender (\%) $\mathrm{N}=347 \mathrm{I}$ & $P$ value \\
\hline Age, mean (SD) & & $22.5(6.0)$ & $22.5(6.8)$ & 0.74 \\
\hline \multicolumn{5}{|l|}{ Race/ethnicity } \\
\hline White & 134,496 & $132,358(6 \mid .05)$ & $2138(61.94)$ & \\
\hline African American & 10,189 & $|0,03|(4.63)$ & I58 (4.58) & \\
\hline Hispanic & 26,174 & $25,808(11.90)$ & $366(10.60)$ & \\
\hline Asian/Pacific Islander & 30,398 & $30,034(13.85)$ & $364(10.54)$ & \\
\hline American Indian, Alaskan & 3377 & $3303(1.52)$ & $74(2.14)$ & \\
\hline \multicolumn{5}{|l|}{ Native or Native Hawaiian } \\
\hline$>1$ race & 9460 & $9243(4.26)$ & $217(6.29)$ & \\
\hline Other & 6163 & $6028(2.78)$ & $135(3.9 \mid)$ & 0.01 \\
\hline \multicolumn{5}{|l|}{ Semester } \\
\hline Spring 2016 & 94,376 & $92,69 \mid(42.50)$ & $1685(48.55)$ & \\
\hline Fall 2016 & 33,176 & $32,706(15.00)$ & $470(13.54)$ & \\
\hline Spring 2017 & 62,798 & $6 I, 959(28.4 I)$ & $839(24.17)$ & \\
\hline Fall 2017 & 31,199 & $30,722(14.09)$ & 477 (I3.74) & $<0.0001$ \\
\hline \multicolumn{5}{|l|}{ Region } \\
\hline Northeast & 47,781 & $46,983(21.54)$ & $798(22.99)$ & \\
\hline Midwest & 45,127 & $44,404(20.36)$ & $723(20.83)$ & \\
\hline South & 48,258 & $47,597(21.83)$ & $661(19.04)$ & \\
\hline West & 80,383 & $79,094(36.27)$ & $1289(37.14)$ & 0.21 \\
\hline \multicolumn{5}{|l|}{ College size (students) } \\
\hline$<2500$ & 22,617 & $22,125(10.15)$ & $492(14.17)$ & \\
\hline $2500-4999$ & 21,713 & $21,348(9.79)$ & $365(10.52)$ & \\
\hline 5000-9999 & 35,757 & $35,236(16.16)$ & $52 I(I 5.01)$ & \\
\hline $10,000-19,999$ & 51,351 & $50,556(23.18)$ & $795(22.90)$ & \\
\hline$\geq 20,000$ & 90,111 & $88,813(40.73)$ & $1298(37.40)$ & $<0.0001$ \\
\hline \multicolumn{5}{|l|}{ Campus setting } \\
\hline Very large city $(>500,000)$ & 59,348 & $58,377(26.77)$ & 971 (27.97) & \\
\hline Large city $(250,000-499,999)$ & 23,269 & $22,936(10.52)$ & $333(9.59)$ & \\
\hline Small city $(50,000-249,999)$ & 75,983 & $74,888(34.34)$ & $1095(31.55)$ & \\
\hline Large town $(10,000-49,999)$ & 47,988 & $47,166(21.63)$ & $822(23.68)$ & \\
\hline Small town $(2500-9,999)$ & 11,940 & II,740 (5.38) & $200(5.76)$ & \\
\hline Rural community $(<2500)$ & 3021 & 2971 (1.36) & $50(1.44)$ & $<0.0001$ \\
\hline \multicolumn{5}{|l|}{ College/university type } \\
\hline 2-year & 12,312 & $12,105(5.55)$ & $207(5.96)$ & \\
\hline$\geq 4$ years & 209,237 & $205,973(94.45)$ & $3264(94.04)$ & 0.29 \\
\hline \multicolumn{5}{|l|}{ Carnegie classification } \\
\hline Associates colleges & 12,312 & $12,105(5.55)$ & $207(5.96)$ & \\
\hline Baccalaureate colleges & 24,100 & $23,558(10.80)$ & $542(15.62)$ & \\
\hline Masters colleges/universities & 55,270 & $54,378(24.94)$ & $892(25.70)$ & \\
\hline Research institutions & 125,111 & $123,357(56.57)$ & I $754(50.53)$ & \\
\hline Special focus institutions & 731 & $728(0.33)$ & $3(0.09)$ & \\
\hline Miscellaneous/not classified & 4025 & $3952(1.81)$ & $73(2.10)$ & $<0.0001$ \\
\hline \multicolumn{5}{|l|}{ Year in school } \\
\hline Ist year undergraduate & 50,059 & $49,257(22.73)$ & $802(23.27)$ & \\
\hline 2nd year undergraduate & $4 I, 4 I 7$ & $40,747(18.80)$ & $670(19.44)$ & \\
\hline
\end{tabular}

(Continued) 
Table 3 (Continued).

\begin{tabular}{|l|c|c|c|c|}
\hline Student Characteristics & N & Cisgender (\%) N=2 18, 078 & Transgender (\%) N=347I & P value \\
\hline 3rd year undergraduate & 43,016 & $42,344(19.54)$ & $672(19.50)$ \\
4th year undergraduate & 35,342 & $34,781(16.05)$ & $561(16.28)$ \\
5th year or more undergraduate & 11,147 & $10,942(5.05)$ & $205(5.95)$ \\
Graduate or professional & 37,037 & $36,547(16.87)$ & $490(14.22)$ \\
Not seeking a degree & 793 & $772(0.36)$ & $21(0.61)$ \\
Other & 1336 & $1311(0.60)$ & $25(0.73)$ \\
\hline
\end{tabular}

Table 4 Canadian Sample: Bivariate Associations Between Transgender Identity, Demographic and College Characteristics in a Sample of 43,340 College/University Students from Canada

\begin{tabular}{|c|c|c|c|c|}
\hline Students Characteristics & $\mathbf{N}$ & Cisgender (\%) N=42, 623 & Transgender (\%) N=717 & $P$ value \\
\hline Age, mean (SD) & & $22.96(5.99)$ & $23.39(8.16)$ & 0.06 \\
\hline \multicolumn{5}{|l|}{ Race/ethnicity } \\
\hline White & 30,437 & $29,959(70.81)$ & $478(67.23)$ & \\
\hline African American & 1396 & $1373(3.25)$ & $23(3.23)$ & \\
\hline Hispanic & 884 & $868(2.05)$ & $16(2.25)$ & \\
\hline Asian/Pacific Islander & 5870 & 5791 (13.69) & $79(11.11)$ & \\
\hline American Indian, Alaskan & 1697 & $1657(3.92)$ & $40(5.63)$ & \\
\hline Native or Native Hawaiian & & & & \\
\hline$>$ I race & $|28|$ & $1417(2.94)$ & $35(4.92)$ & 0.0004 \\
\hline \multicolumn{5}{|l|}{ College size (students) } \\
\hline$<2500$ & 592 & $576(1.35)$ & $16(2.23)$ & \\
\hline $2500-4999$ & 1174 & $1152(2.70)$ & $22(3.07)$ & \\
\hline 5000-9999 & 8304 & $8170(19.17)$ & $134(18.69)$ & \\
\hline $10,000-19,999$ & 10,839 & $10,663(25.02)$ & $176(24.55)$ & \\
\hline$\geq 20,000$ & 22,431 & $22,062(51.76)$ & $369(51.46)$ & 0.36 \\
\hline \multicolumn{5}{|l|}{ Campus setting } \\
\hline Very large city $(>500,000)$ & 19,533 & $19,207(45.06)$ & $326(45.47)$ & \\
\hline Large city $(250,000-499,999)$ & 7321 & $7177(16.84)$ & 144 (20.08) & \\
\hline Small city $(50,000-249,999)$ & 16,328 & $16,082(37.73)$ & $246(34.3 I)$ & \\
\hline Small town (2500-9999) & 158 & $157(0.37)$ & I $(0.14)$ & 0.19 \\
\hline \multicolumn{5}{|l|}{ College/university type } \\
\hline 2-year & $|27|$ & $1253(2.94)$ & $18(2.5 \mathrm{I})$ & \\
\hline$\geq 4$ years & 32,768 & $32,237(75.63)$ & $531(74.06)$ & \\
\hline Other & 9301 & $9133(21.43)$ & $168(23.43)$ & 0.15 \\
\hline \multicolumn{5}{|l|}{ Year in school } \\
\hline Ist year undergraduate & 9907 & $9727(22.96)$ & $180(25.25)$ & \\
\hline 2nd year undergraduate & 8807 & 8677 (20.48) & $130(18.23)$ & \\
\hline $3 r d$ year undergraduate & 8005 & $7876(18.59)$ & $129(18.09)$ & \\
\hline 4th year undergraduate & 6303 & $6197(14.62)$ & $106(14.87)$ & \\
\hline 5 th year or more undergraduate & 2851 & $2795(6.60)$ & $56(7.85)$ & \\
\hline Graduate or professional & 5994 & $5917(13.96)$ & $77(10.80)$ & \\
\hline Not seeking a degree & 436 & $421(0.99)$ & $15(2.10)$ & \\
\hline Other & 783 & $763(1.80)$ & $20(2.8 I)$ & 0.95 \\
\hline
\end{tabular}


Table 5 Transgender Identity Among the US and Canadian College Students

\begin{tabular}{|l|l|l|l|l|}
\hline & $\begin{array}{l}\text { Trans } \\
\text { Woman }\end{array}$ & $\begin{array}{l}\text { Trans } \\
\text { Man }\end{array}$ & Genderqueer & $\begin{array}{l}\text { Another Identity } \\
\text { (Please Specify) }\end{array}$ \\
\hline $\begin{array}{l}\text { US } \\
\text { Canada }\end{array}$ & $\begin{array}{l}137 \\
35\end{array}$ & 338 & $\begin{array}{l}1310 \\
203\end{array}$ & $\begin{array}{l}1951 \\
365\end{array}$ \\
\hline
\end{tabular}

white, attended a school with a student size between 5000 through $\leq 20,000+$ with a campus setting of small town to large city (population of 10,000 through 249,999). Many institutions appear to have the ability to conduct advanced degree or research as $76.2 \%$ transgender students attended school with masters colleges/universities or research institutions.

Country-specific associations between transgender identity and sleep disturbances are presented in Table 6. Transgender students were approximately $30 \%$ more likely to indicate inadequate sleep duration to feel rested as compared with their cisgender peers in both countries. Similarly, frequent daytime sleepiness was higher in transgender students in both countries. US transgender students were more likely to wake too early compared to cisgender students; OR 1.36 (95\% CI 1.26, 1.48). In both countries, transgender students had about $40 \%$ higher odds of feeling tired, dragging and sleepy during the day, and higher odds for difficulty falling asleep. This common insomnia symptom had a slightly stronger association among US students compared to Canadian students ( $\mathrm{P}$, interaction $=0.08$ ). Odds of insomnia diagnosis or treatment were 2.8-fold and 2.5 fold among US and Canadian transgender students, respectively, in comparison to cisgender students. Similarly, odds of diagnosis or treatment of any sleep disorders were more than twice as high in US or Canadian transgender students compared to cisgender.

Table 7 presents country-specific associations between transgender identity and mental health outcomes. Formal interaction analysis suggests that about half of the associations varied significantly by country. Overall, the burden of poor mental health is significantly higher among transgender vs cisgender students. The odds of a diagnosis or treatment of depression is almost 3-fold and 2.4-fold among transgender students in the US and Canada compared with cisgender students, respectively. Similarly, anxiety diagnosis or treatment odds were 2-fold higher in transgender college students with a stronger association among US students than Canadian. Higher odds of negative feelings such as hopelessness, overwhelmed, exhausted, lonely, sad depressed, anxious, or angry, were also observed in transgender vs cisgender students. Similarly, higher self-harm odds were observed in transgender students in both countries. To illustrate, the odds of committing self-harm, considering suicide or attempting suicide are 3.87 (95\% CI 3.56, 4.21), 3.45 (95\% 3.19, $3.72)$ and $4.21(3.59,4.94)$ among US transgender vs cisgender students.

In sensitivity analyses which included a difference in transgender classification (students with a difference between gender assigned at birth and gender identity or subjects that did not identify as transgender), results remained unchanged.

\section{Discussion}

This large study of North American college students investigated the associations between transgender identity, sleep, mental health, and suicidality. The prevalence of transgender identity was 4-times higher than the reported transgender prevalence of $0.3-0.5 \%$ in the general population. $^{21}$ Alarmingly, transgender students had a 2-fold higher odds of insomnia diagnosis, sleep and mood disorders, and a 3-4 fold higher odds of suicidal thoughts and attempts. Associations between transgender identity and sleep were similar in the US versus Canada, while associations between transgender identity and poor mental health were stronger in the US. ${ }^{21}$

This study found that transgender individuals were more likely to have inadequate sleep, daytime sleepiness, insomnia symptoms, and a diagnosis of a sleep disorder. Data on sleep among transgender individuals are limited. In a recent review on sleep among gender minority participants, only 4 of 31 studies included transgender subjects. ${ }^{34}$ Poor sleep quality is prevalent in non-college transgender women (79.2\%) and transgender men $(81.2 \%) .{ }^{13}$ A qualitative study of transgender adults, of which $25 \%$ were between the ages of 18-21 years-old, observed high proportions of poor sleep quality. Both mood and gender dysphoria had a negative impact on sleep quality. ${ }^{15}$ Short sleep ( $<5$ hours) was also common among transgender adults, estimated as $15 \%$ and $13.2 \%$ in transgender women and men, respectively and with a higher prevalence among transgender gender nonconforming (35.5\%) subjects. ${ }^{18}$ The prevalence of sleep disorders is nearly unknown among transgender people. A case series that included only 3 patients found that 2 transgender men developed obstructive sleep apnea after starting sex hormone therapy. ${ }^{35}$ 
Table 6 Associations Between Transgender Identity and Sleep Disturbances Among College/University Students in US and Canada

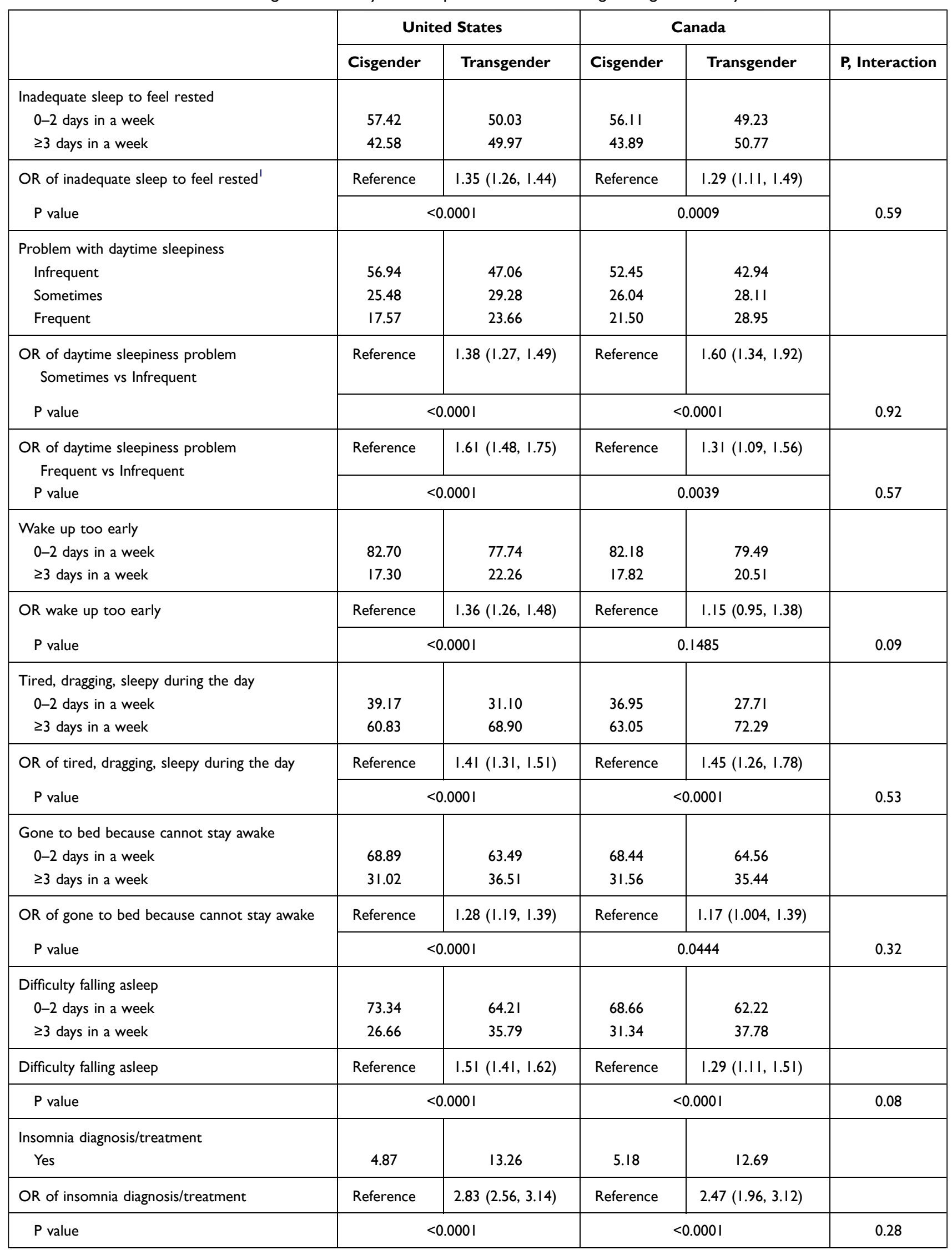

(Continued) 
Table 6 (Continued).

\begin{tabular}{|c|c|c|c|c|c|}
\hline & \multicolumn{2}{|c|}{ United States } & \multicolumn{2}{|c|}{ Canada } & \multirow[b]{2}{*}{ P, Interaction } \\
\hline & Cisgender & Transgender & Cisgender & Transgender & \\
\hline \multicolumn{6}{|l|}{ Sleep disorders diagnosis/treatment } \\
\hline Yes & 2.43 & 6.01 & 3.29 & 7.34 & \\
\hline OR of sleep disorders diagnosis/treatment & Reference & $2.45(2.14,2.87)$ & Reference & $2.29(1.71,3.05)$ & \\
\hline$P$ value & \multicolumn{2}{|c|}{$<0.0001$} & \multicolumn{2}{|c|}{$<0.0001$} & 0.59 \\
\hline
\end{tabular}

This study showed that transgender college students had a $2-3$ fold increased odds of depression and anxiety. Accumulated evidence demonstrates that transgender students have higher rates of depression than cisgender peers. ${ }^{9,22,23,28,36}$ Our findings corroborate a recent study among transgender college students that showed a 4-fold increase in at least one mood or mental health problem. ${ }^{22}$ Transgender college students had a disturbing prevalence of suicidal thoughts (68\%), attempts (38\%) and self-harm $(65 \%) .{ }^{11}$ A multi-national sample of transgender youth reported suicidal behaviors among $29-48 \%$ of participants. ${ }^{37,38}$

Sleep, mood, and suicidality are intricately linked. ${ }^{21,39-41}$ Insomnia and depression independently and jointly impact suicide, regardless of gender identity. ${ }^{39}$ In cisgender adolescents with insomnia symptoms, a 2-fold increased risk of suicidality is present even without a mental health comorbidity. ${ }^{42}$ Depressed cisgender adolescents have a $3-4$ fold higher risk of insomnia as compared to non-depressed peers. ${ }^{43}$ The severity of depression is strongly associated with suicide and non-fatal suicidal behaviors. ${ }^{40}$ These stressors can adversely affect both sleep and mood. These data support screening for suicidal ideation as a priority for transgender students with depression, insomnia or an increase in sleep complaints.

Minority stress theory, sex hormones, and serotonin are potential mechanisms that link sleep disturbances, mental health, and suicide. The minority stress theory states that prejudice and discrimination increase the risk of chronic, psychosocial stressors that can lead to negative health problems in individuals with a minority identity. ${ }^{44}$ Transgender individuals often experience negative psychosocial circumstances (i.e. denied access to genderaffirming bathrooms), violence, poor social and familial support, misgendering, delay in gender transition, unstable housing, discrimination, and school or employment difficulties. ${ }^{22,37,38,45,46}$ These experiences can increase arousal, vigilance, distress, as well as physiological reactivity, and consequently impair sleep. ${ }^{36}$ Minority stress can also adversely impair mental health among transgender individuals. ${ }^{47}$ The minority stress that transgender individuals may experience can contribute or result in poor mental and sleep health.

The campus environment may not be supportive of transgender students and can contribute to minority stress. ${ }^{48}$ Gender-inclusive or single stall restrooms are rare or nonexistent as is gender-inclusive housing. School documents often will have only male and female categorical options or may not distinguish between sex and gender. Some school-related health care insurances will not cover hormone treatments. Many institutions do not have gender as part of their nondiscrimination policies; although that has been decreasing over the last decade.

Changes in policy and environment may help transgender college students. Encouragingly, community connectedness decreases sleep disturbances. ${ }^{49,50}$ Improvement in state-level policies for other minority groups, such as lesbian, gay, and bisexual groups, have led to an improvement in health. ${ }^{51}$ In a study among cisgender college students, students with higher rates of sleep satisfaction had significantly lower rates of mental health crises and suicidal ideation. ${ }^{52}$ Improving the campus climate for transgender students through policy and both the social and physical environment could potentially help both the mental and sleep health of transgender college students. However, future research is needed.

Serotonin (5-HT) has a role both in suicide and in the regulation of sleep. ${ }^{39}$ Poor sleep can also heighten negative emotions such as sadness and hopelessness. ${ }^{53}$ Negative mood states are associated with insomnia symptoms and sleep disturbance. ${ }^{54}$

Mechanistically, sex hormone therapy as a gender affirming treatment is a potential cause for sleep disturbances. Transgender men seek therapy with exogenous 
Table 7 Associations Between Transgender Identity and Mental Health Measures Among College Students in the US and Canada

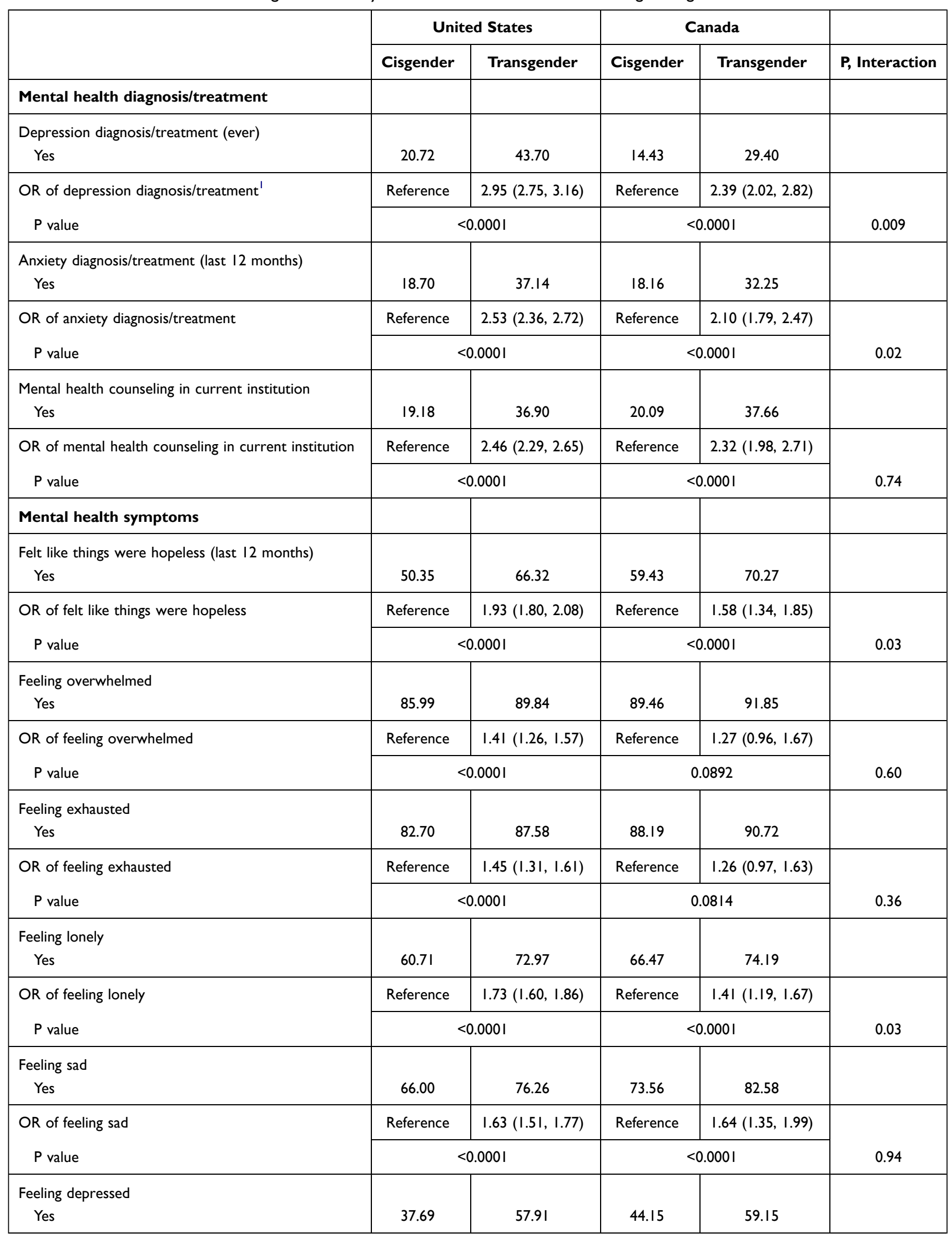


Table 7 (Continued).

\begin{tabular}{|c|c|c|c|c|c|}
\hline & \multicolumn{2}{|c|}{ United States } & \multicolumn{2}{|c|}{ Canada } & \multirow[b]{2}{*}{ P, Interaction } \\
\hline & Cisgender & Transgender & Cisgender & Transgender & \\
\hline \multirow[t]{2}{*}{ OR of feeling depressed } & Reference & $2.26(2.11,2.42)$ & Reference & $1.80(1.55,2.10)$ & \\
\hline & \multicolumn{2}{|c|}{$<0.0001$} & \multicolumn{2}{|c|}{$<0.0001$} & 0.009 \\
\hline \multicolumn{6}{|l|}{ Feeling anxious } \\
\hline \multirow{2}{*}{$\begin{array}{l}\text { OR of feeling anxious } \\
P \text { value }\end{array}$} & Reference & $1.94(1.77,2.10)$ & Reference & $1.84(1.54,2.20)$ & \\
\hline & \multicolumn{2}{|c|}{$<0.0001$} & \multicolumn{2}{|c|}{$<0.0001$} & 0.64 \\
\hline \multicolumn{6}{|l|}{$\begin{array}{l}\text { Feeling anger } \\
\text { Yes }\end{array}$} \\
\hline Yes & 39.80 & 52.17 & 47.15 & 55.45 & \\
\hline \multirow[t]{2}{*}{ OR of feeling angry } & Reference & $1.63(1.53,1.75)$ & Reference & $1.34(1.18,1.59)$ & \\
\hline & \multicolumn{2}{|c|}{$<0.0001$} & \multicolumn{2}{|c|}{$<0.0001$} & 0.04 \\
\hline \multicolumn{6}{|l|}{ Self-harm } \\
\hline Yes & 6.72 & $22.4 I$ & 8.51 & 18.57 & \\
\hline \multirow{2}{*}{$\begin{array}{l}\text { OR of committing self-harm } \\
\mathrm{P} \text { value }\end{array}$} & Reference & $3.87(3.56,4.21)$ & Reference & $2.34(1.96,2.89)$ & \\
\hline & \multicolumn{2}{|c|}{$<0.0001$} & \multicolumn{2}{|c|}{$<0.0001$} & $<0.0001$ \\
\hline \multirow{2}{*}{\multicolumn{6}{|c|}{$\begin{array}{l}\text { Considered suicide } \\
\text { Yes }\end{array}$}} \\
\hline & & & & & \\
\hline \multirow[t]{2}{*}{ OR of considering suicide } & Reference & $3.45(3.19,3.72)$ & Reference & $2.45(2.10,2.95)$ & \\
\hline & \multicolumn{2}{|c|}{$<0.0001$} & \multicolumn{2}{|c|}{$<0.0001$} & 0.0006 \\
\hline \multicolumn{6}{|l|}{ Suicide attempted } \\
\hline Yes & 1.23 & 5.17 & 2.00 & 7.48 & \\
\hline \multirow[t]{2}{*}{ OR of attempting suicide } & Reference & $4.21(3.59,4.94)$ & Reference & $3.92(2.93,5.24)$ & \\
\hline & \multicolumn{2}{|c|}{$<0.0001$} & \multicolumn{2}{|c|}{$<0.0001$} & 0.39 \\
\hline
\end{tabular}

testosterone for virilization, while transgender women use anti-androgen therapy with feminizing exogenous estrogens to suppress androgenic effects. ${ }^{21}$ Little current literature is available on the impact of SHT on sleep among transgender individuals. ${ }^{55}$ Nightly sweating correlated with poor sleep quality among transgender men, but not transgender women, likely through a history of a gonadectomy. ${ }^{13}$ Testosterone hormone therapy and decreased estrogen can cause or worsen obstructive sleep apnea, while feminizing sex hormone therapy can improve obstructive sleep apnea. ${ }^{19,20,35,56}$ Among cisgender individuals the post-menopausal state is associated with insomnia. ${ }^{19,57}$ Theoretically, changes in estrogen and progesterone among transgender men undergoing male affirming sex hormone therapy may be analogous to the hormonal changes experienced by menopausal women. Testosterone administration among testosterone-deficient men (cisgender) is associated with increased insomnia symptoms. ${ }^{58}$ Based on this literature, screening for sleep disorders among transgender students starting SHT could be considered.

\section{Prevalence of Mood and Sleep Disturbances by Country}

This study found an association between transgender identity and mood disorders among US and Canadian students. However, the magnitude of this association was significantly lower among Canadian students in comparison to their US peers. The attenuated association between 
transgender identity and mood among Canadian students may be attributed to the Canadian social and legal climate, both at the national and campus level. Canada has introduced policies in support of sexual and gender protection. ${ }^{59,60}$ In 2017 gender identity was added to the Canadian Human Rights Act and the Criminal Code. Canadians can indicate that they do not identify as male or female on their passports. In the US it was in 2020 that the Supreme Court ruled that the 1964 Civil Rights Act provided employment protections for LGBT individuals. At the school level, some protection may be present based on Title VII. ${ }^{59,61}$ Data on institutional support of LGBTQ students in the US compared to Canada is minimal, yet suggests that Canadian institutions provide more support. Among 1751 US post-secondary institutions with an undergraduate focus, $8 \%$ had a LGBT Resource Centers in contrast to a national sample of $73 \%$ and $35 \%$ of Canadian universities and colleges, respectively. ${ }^{36,62,63}$

\section{Strengths and Limitations}

This study has multiple strengths. First, the examination of sleep and mental health in relation to transgender college students utilized a large, North American sample. Second, the study population is diverse with respect to students' backgrounds and institution types. Third, the availability of student and institutional characteristics allowed their inclusion as confounders in the analyses. Finally, the ACHA-NCHA II survey shows strong reliability over the years of administration. ${ }^{30}$ However, the present study has some limitations. First, this sample may not be representative across institutions of higher education, as participation in this survey is greater among ACHA member institutions. The higher participation rates for ACHA member institutions may relate to lower survey costs and increased awareness of the survey itself. Additionally, this population may have an increased white student population; according to the US Census, $54.7 \%$ of college students were non-Hispanic white. ${ }^{64}$ Nonetheless, this is a large sample of college students from institutions throughout the United States and Canada. Second, the participating students may not represent the entire student population in their respective institutions. Third, while sleep and mood symptoms and diagnoses are selfreported, these self-report questions are commonly utilized to screen for sleep and mood disorders in clinical and research settings. ${ }^{65,66}$ This study did not evaluate the use of sex hormone therapy therefore mechanistic implications are theoretical. Finally, this cross-sectional study design does not allow examination of temporal associations between transgender identity, sleep and mental health outcomes, and suicidality.

\section{Conclusion}

The burden of sleep and mood disturbances among transgender college students is a substantial public health concern, while the risk of suicidality is a public health crisis. Screening for sleep and mood disorders as well as suicidality is vital for transgender college students. Identification of modifiable risk factors for suicidality, mental health and sleep disturbances in transgender students could inform the design of effective interventions. Adoption of policies that promote diversity, inclusion and equity, in particular genderaffirming policies, may have a positive impact on the sleep, mood and suicidality of transgender college students.

\section{Disclaimer}

The opinions, findings, and conclusions presented/reported in this article/presentation are those of the author(s), and are in no way meant to represent the corporate opinions, views, or policies of the American College Health Association (ACHA). ACHA does not warrant nor assume any liability or responsibility for the accuracy, completeness, or usefulness of any information presented in this article/presentation.

\section{Abbreviations}

ACHA-NCHA II, American College Health AssociationNational College Health Assessment II; LGBQ, Lesbian, Gay, Bisexual and Queer; ACHA, American College Health Association.

\section{Data Sharing Statement}

American College Health Association-National College Health Assessment II link to request data. https://www. acha.org/NCHA/ACHA-NCHA_Data/Research_Projects and Data Access/NCHA/Data/Research Projects and Data_Access.aspx?hkey=e21ae975-78e6-4805-b247e79564a42a9a.

Portions of the ACHA-NCHA Reference Group data set may be made available for independent analysis. Interested investigators are encouraged to submit proposals. Research is being conducted in the areas of nutrition, weight and eating disorders; $\mathrm{BAC}$ and binge drinking; alcohol and marijuana as impediments to academic performance; and depression and suicide ideation. Contact Christine Kukich, at ckukich@acha.org, for further 
information regarding access to the NCHA Reference Group data.

\section{Acknowledgment}

We would like to thank the American College Health Association for the opportunity to complete this research.

\section{Author Contributions}

$\mathrm{SH}$ developed the research question, statistical analysis plan, and co-drafted the manuscript. EJ developed the research question and statistical analysis plan, analyzed and interpreted data, and edited the manuscript. LM codrafted the manuscript. RG co-drafted the manuscript. $\mathrm{MH}$ developed the research question and statistical analysis plan, analyzed and interpreted data, and edited the manuscript GLD co-designed the statistical analysis plan, data interpretation, created the tables and co-drafted the manuscript. All authors made substantial contributions to conception and design, acquisition of data, or analysis and interpretation of data; took part in drafting the article or revising it critically for important intellectual content; agreed to submit to the current journal; gave final approval of the version to be published; and agree to be accountable for all aspects of the work.

\section{Funding}

No funding source was used for this study.

\section{Disclosure}

Dr Mary Hoban reports being an employee of the American College Health Association, outside the submitted work. The authors report no other potential conflicts of interest for this work.

\section{References}

1. American College Health Association. American College Health Association-National College Health Assessment II reference group executive summary spring 2018; 2018. https://www.acha.org/docu ments/ncha/NCHA-II_Spring_2018_Reference_Group_Data_Report. pdf. Accessed October 4, 2020.

2. Lipson SK, Kern A, Eisenberg D, Breland-Noble AM. Mental health disparities among college students of color. $J$ Adolesc Health. 2018;63 (3):348-356. doi:10.1016/j.jadohealth.2018.04.014

3. Garlow SJ, Rosenberg J, Moore JD, et al. Depression, desperation, and suicidal ideation in college students: results from the American Foundation for Suicide Prevention College Screening Project at Emory University. Depress Anxiety. 2008;25(6):482-488.

4. Becker SP, Jarrett MA, Luebbe AM, Garner AA, Burns GL, Kofler MJ. Sleep in a large, multi-university sample of college students: sleep problem prevalence, sex differences, and mental health correlates. Sleep Health. 2018;4(2):174-181.
5. Concepcion T, Barbosa C, Velez JC, et al. Daytime sleepiness, poor sleep quality, eveningness chronotype, and common mental disorders among Chilean college students. J Am Coll Health. 2014;62 (7):441-448.

6. Edwards-Leeper L, Spack NP. Psychological evaluation and medical treatment of transgender youth in an interdisciplinary "Gender Management Service" (GeMS) in a major pediatric center. J Homosex. 2012;59(3):321-336.

7. Rafferty J. Ensuring comprehensive care and support for transgender and gender-diverse children and adolescents. Pediatrics. 2018;142 (4): 20182162.

8. Daniel H, Butkus R. Lesbian, gay, bisexual, and transgender health disparities: executive summary of a policy position paper from the American College of Physicians LGBT health disparities. Ann Intern Med. 2015;163(2):135-137.

9. Greathouse M, BrckaLorenz A, Hoban M, Huesman R, Rankin S, Bara Stolzenberg E. Queer-spectrum and trans-spectrum student experiences in American higher education. 2018.

10. Hershner SD, Chervin RD. Causes and consequences of sleepiness among college students. Nat Sci Sleep. 2014;6:73-84. doi:10.2147/ NSS.S62907

11. Liu CH, Stevens C, Wong SHM, Yasui M, Chen JA. The prevalence and predictors of mental health diagnoses and suicide among U.S. college students: implications for addressing disparities in service use. Depress Anxiety. 2019;36(1):8-17. doi:10.1002/da.22830

12. American Psychiatric Association. Diagnostic and Statistical Manual of Mental Disorders. Fifth Edition. American Psychiatric Association; 2013.

13. Auer MK, Liedl A, Fuss J, et al. High impact of sleeping problems on quality of life in transgender individuals: a cross-sectional multicenter study. PLoS One. 2017;12(2):e0171640-e0171640. doi:10.1371/journal.pone. 0171640

14. Messman JB, Leslie LA. Transgender college students: academic resilience and striving to cope in the face of marginalized health. $\mathrm{J} \mathrm{Am} \mathrm{Coll} \mathrm{Health.}$ 2019;67(2):161-173. doi:10.1080/07448481.2018.1465060

15. Harry-Hernandez S, Reisner S, Schrimshaw E, et al. Gender dysphoria, mental health, and poor sleep health among transgender and gender nonbinary individuals: a qualitative study in New York city. Transgender Health. 2020;5(1):59-68. doi:10.1089/trgh.2019.0007

16. Slopen N, Lewis TT, Williams DR. Discrimination and sleep: a systematic review. Sleep Med. 2016;18:88-95. doi:10.1016/j. sleep.2015.01.012

17. Huynh VW, Gillen-O'Neel C. Discrimination and sleep: theprotective role of school belonging. Youth Soc. 2016;48(5):649-672. doi: $10.1177 / 0044118 \times 13506720$

18. Dai H, Hao J. Sleep deprivation and chronic health conditions among sexual minority adults. Behav Sleep Med. 2019;17(3):254-268. doi:10.1080/15402002.2017.1342166

19. Manber R, Armitage R. Sex, steroids, and sleep: a review. Sleep. 1999;22(5):540-541.

20. Hoyos CM, Killick R, Yee BJ, Grunstein RR, Liu PY. Effects of testosterone therapy on sleep and breathing in obese men with severe obstructive sleep apnoea: a randomized placebo-controlled trial. Clin Endocrinol (Oxf). 2012;77(4):599-607. doi:10.1111/j.1365-2265.2012.04413.x

21. Unger CA. Hormone therapy for transgender patients. Transl Androl Urol. 2016;5(6):877-884. doi:10.21037/tau.2016.09.04

22. Lipson SK, Raifman J, Abelson S, Reisner SL. Gender minority mental health in the U.S.: results of a national survey on college campuses. Am J Prev Med. 2019;57(3):293-301. doi:10.1016/j. amepre.2019.04.025

23. Connolly MD, Zervos MJ, Barone CJ, Johnson CC, Joseph CLM. The mental health of transgender youth: advances in understanding. $J$ Adolesc Health. 2016;59(5):489-495. doi:10.1016/j.jadohealth.2016.06.012

24. Swanbrow BMA, Nemeth RSF, Ritts SM, Branagan WT, Warner AR, Clark SL. Supporting transgender college students: implications for clinical intervention and campus prevention. J College Stud Psychother. 2017;31 (2):155-176. doi:10.1080/87568225.2016.1253441 
25. Beemyn B, Curtis B, Davis M, Jean Tubbs N. Transgender issues on college campuses. $N$ Directions Student Services. 2005;2005 (111):49-60. doi:10.1002/ss.173

26. Goldberg AE, Kuvalanka KA, Budge SL, Benz MB, Smith JZ. Health care experiences of transgender binary and nonbinary university students. Couns Psychol. 2019;47(1):59-97.

27. James SE, Herman JL, Rankin S, Keisling M, Mottet L, Anafi M The report of the 2015 U.S. transgender survey. Washington, DC: National Center for Transgender Equality. National Center for Transgender Equality; 2016. Available from: https:/www.transequal ity.org/sites/default/files/docs/USTS-Full-Report-FINAL.PDF. Accessed February 15, 2021.

28. Burczycka M Students' experiences of discrimination based on gender, gender identity or sexual orientation at postsecondary schools in the Canadian provinces, 2019. Canadian Centre for Justice and Community Safety Statistics Web site; 2020. https://www150.stat can.gc.ca/n1/en/pub/85-005-x/2020001/article/00001-eng.pdf?st= mhuVn0KH. Accessed November 22, 2020.

29. American College Health Association National College Health Assessment II. ACHA-NCHA Web Version Frequently Asked Questions REVISED; 2020. https:/www.acha.org/NCHA/To_ Participate/FAQs/NCHA/To_Participate/FAQ.aspx?hkey=7d4e7ad74103-44e2-8980-da5e30c70860. Accessed January 6, 2021.

30. American College Health Association. American College Health Association-National College Health Assessment II: Reliability and Validity Analyses 2011; published 2013. Available from: . Accessed 5 March 2021https://www.acha.org/documents/NCHA/ACHANCHAII_RELIABILITY_AND_VALIDITY_ANALYSES.pdf.

31. American Academy of Sleep Medicine. International Classification of Sleep Disorders: Diagnostic and Coding Manual. 3rd Edition ed. Westchester, Illinois: American Academy of Sleep Medicine; 2014.

32. Kim H, Young T. Subjective daytime sleepiness: dimensions and correlates in the general population. Sleep. 2005;28(5):625-634.

33. American College Health Association. American College Health Association-National College Health Assessment II reference group executive summary spring; 2016. Available from: http:/www.acha-ncha.org/docs/ NCHAII\%20SPRING\%202016\%20US\%20REFERENCE\%20GROUP\% 20EXECUTIVE20SUMMARY.pdf. Accessed November 15, 2019.

34. Butler ES, McGlinchey E, Juster RP. Sexual and gender minority sleep: a narrative review and suggestions for future research. J Sleep Res. 2019.

35. Robertson B, Lerner B, Collen J, Smith PR. The effects of transgender hormone therapy on sleep and breathing: a case series. J Clin Sleep Med. 2019.

36. Martin-Storey A, Legault R, Prickett KC. Sleep and its disorders among sexual and gender minority populations. In: Attarian $\mathrm{H}$, ViolaSaltzman M, editors. Sleep Disorders in Women: A Guide to Practical Management. Cham: Springer International; 2020:83-98.

37. Strauss P, Cook A, Winter S, Watson V, Wright Toussaint D, Lin A. Associations between negative life experiences and the mental health of trans and gender diverse young people in Australia: findings from trans pathways. Psychol Med. 2019;1-10.

38. Hunt QA, Morrow QJ, McGuire JK. Experiences of suicide in transgender youth: a qualitative, community-based study. Arch Suicide Res. 2019;1-16.

39. Bernert RA, Joiner TE. Sleep disturbances and suicide risk: a review of the literature. Neuropsychiatr Dis Treat. 2007;3(6):735-743.

40. Hawton K, Casañas i Comabella C, Haw C, Saunders K. Risk factors for suicide in individuals with depression: a systematic review. $J$ Affect Disord. 2013;147(1):17-28.

41. Konjarski M, Murray G, Lee VV, Jackson ML. Reciprocal relationships between daily sleep and mood: a systematic review of naturalistic prospective studies. Sleep Med Rev. 2018;42:47-58.

42. Blank M, Zhang J, Lamers F, Taylor AD, Hickie IB, Merikangas KR. Health correlates of insomnia symptoms and comorbid mental disorders in a nationally representative sample of US adolescents. Sleep. 2015;38(2):197-204.
43. Sivertsen B, Harvey AG, Lundervold AJ, Hysing M. Sleep problems and depression in adolescence: results from a large population-based study of Norwegian adolescents aged 16-18 years. Eur Child Adolesc Psychiatry. 2014;23(8):681-689.

44. Meyer IH. Prejudice, social stress, and mental health in lesbian, gay, and bisexual populations: conceptual issues and research evidence. Psychol Bull. 2003;129(5):674.

45. McKinney JS. On the margins: a study of the experiences of transgender college students. J Gay Lesbian Issues Educ. 2005;3(1):63-76.

46. Seelman KL. Transgender adults' access to college bathrooms and housing and the relationship to suicidality. J Homosex. 2016;63 (10):1378-1399.

47. Chodzen G, Hidalgo MA, Chen D, Garofalo R. Minority stress factors associated with depression and anxiety among transgender and gender-nonconforming youth. $J$ Adolesc Health. 2019;64(4):467-471.

48. Goldberg AE Transgender Students in Higher Education. The Williams Institute; 2018. Available from: https://vtechworks.lib.vt. edu/handle/10919/86955. Accessed November 22, 2020.

49. Kolp H, Wilder S, Andersen C, et al. Gender minority stress, sleep disturbance, and sexual victimization in transgender and gender nonconforming adults. J Clin Psychol. 2020;76(4):688-698.

50. Breslow AS, Brewster ME, Velez BL, Wong S, Geiger E, Soderstrom B. Resilience and collective action: exploring buffers against minority stress for transgender individuals. Psychol Sex Orient Gender Diversity. 2015;2(3):253-265.

51. Hatzenbuehler ML, Keyes KM, Hasin DS. State-level policies and psychiatric morbidity in lesbian, gay, and bisexual populations. Am J Public Health. 2009;99(12):2275-2281.

52. Berg SS, Rosenau PS, Prichard JR. Sleep quality mediates the relationship between traumatic events, psychological distress, and suicidality in college undergraduates. J Am Coll Health. 2020;1-4.

53. Ong JC, Cardé NB, Gross JJ, Manber R. A two-dimensional approach to assessing affective states in good and poor sleepers. J Sleep Res. 2011;20(4):606-610.

54. Vandekerckhove M, Weiss R, Schotte C, et al. The role of presleep negative emotion in sleep physiology. Psychophysiology. 2011;48 (12):1738-1744

55. Earl DC, Brown LK. On not knowing what we don't know to knowing what we don't know: obstructive sleep apnea in the transgender community. J Clin Sleep Med. 2019;15(10):1393-1395.

56. Huang T, Lin BM, Redline S, Curhan GC, Hu FB, Tworoger SS. Type of menopause, age at menopause, and risk of developing obstructive sleep apnea in postmenopausal women. Am J Epidemiol. 2018;187(7):1370-1379.

57. Orff HJ, Meliska CJ, Martinez LF, Parry BL. The influence of sex and gonadal hormones on sleep disorders. Chrono Physiol Ther. 2014;4:15-25.

58. Liu PY, Yee B, Wishart SM, et al. The short-term effects of high-dose testosterone on sleep, breathing, and function in older men. J Clin Endocrinol Metab. 2003;88(8):3605-3613.

59. Hunt G, Pelz M. Transgender rights in Canada: legal, medical and labour union activities. In: Köllen T, editor. Sexual Orientation and Transgender Issues in Organizations: Global Perspectives on LGBT Workforce Diversity. Cham: Springer International Publishing; 2016:133-147.

60. Bowal P, Smith S. Equality rights for transgender individuals in Canada; 2018. Available from: https://prism.ucalgary.ca/bitstream/ handle/1880/107564/Bowal_EqualityRights2017_LawNow.pdf? sequence=1. Accessed September 8, 2019.

61. Stroumsa D. The state of transgender health care: policy, law, and medical frameworks. Am J Public Health. 2014;104(3):e31-e38.

62. Fine LE. The context of creating space: assessing the likelihood of college LGBT center presence. J Coll Stud Dev. 2012;53(2):285-299.

63. Ecker J, Rae J, Bassi A. Showing your pride: a national survey of queer student centres in Canadian colleges and universities. High Educ. 2015;70(5):881-898. 
64. Velez D. More than 76 million students enrolled in U.S. schools, census bureau reports. US census bureau. 2018. Available from: https://www.census.gov/newsroom/press-releases/2018/school-enroll ment.html. Accessed April 12, 2020.

65. Sanchez-Villegas A, Schlatter J, Ortuno F, et al. Validity of a self-reported diagnosis of depression among participants in a cohort study using the structured clinical interview for DSM-IV (SCID-I). BMC Psychiatry. 2008;8(1):43.
66. Biddle DJ, Robillard R, Hermens DF, Hickie IB, Glozier N. Accuracy of self-reported sleep parameters compared with actigraphy in young people with mental ill-health. Sleep Health. 2015;1(3):214-220.

\section{Publish your work in this journal}

Nature and Science of Sleep is an international, peer-reviewed, open access journal covering all aspects of sleep science and sleep medicine, including the neurophysiology and functions of sleep, the genetics of sleep, sleep and society, biological rhythms, dreaming, sleep disorders and therapy, and strategies to optimize healthy sleep.
The manuscript management system is completely online and includes a very quick and fair peer-review system, which is all easy to use. Visit http://www.dovepress.com/testimonials.php to read real quotes from published authors. 